\title{
ARTLOG: ARCHIVING THE ARTISTIC PROCESS
}

\author{
(1)Yvonne Desmond (2)John McAuley (2)Evin McCarthy,(2) Dr. Ciaran McDonnell, \\ (2) Charles Pritchard (3) Dr. Pat Donlon \\ (1)DIT Library Services \\ (2)Digital Media Centre, DIT \\ (3)Tyrone Guthrie Centre, Newbliss, Co. Monaghan \\ yvonne.desmond@dit.ie
}

\begin{abstract}
Currently there is little or no formal attempt to document the processes an Irish artist undergoes when producing a piece of art. With Artlog we aim to provide the artistic community at the Tyrone Guthrie Centre, Annaghmakerring, Co. Monaghan with a forum to not only develop their profile as an artist but also to document their work practices. In this paper we describe how Artlog came about, the relationship between the aesthetics and the importance of heritage, the approach of the project team in organising the archive and finally how interdisplinary collaboration has impacted the project.
\end{abstract}

\section{INTRODUCTION}

ArtLog is a collaborative venture between the Library Services and the Digital Media Centre of the Dublin Institute of Technology, and the Tyrone Guthrie Centre ${ }^{1}$, Annaghmakerring, Co. Monaghan. The objective of this project (ArtLog) is to build an electronic archive of artistic thought, to capture, organise and preserve this data and make it accessible to future generations. The Tyrone Guthrie Centre is a residential retreat for practising artists. Jointly funded by the Arts Council of Northern Ireland and the Arts Council, it is one of the longest lasting examples of North/South cooperation on the island of Ireland. Over the last twenty seven years it has played host to the vast majority of art practitioners in Ireland (approx. 5000 in number), many of whom have made repeat visits. If this project achieves its objectives it is envisaged that it will provide a scholarly resource for research into Ireland's artistic output and a working model for other organisations in the Arts who might find it useful to record their process. To this end, generous funding has been received from the Irish Arts Council ${ }^{2}$.

This paper discusses the background to the project, the theory that underpins it, the central position of the art maker, the design of a system that facilitates reflective selfarchiving, the development of search and retrieval mechanisms and how the collaboration between information professionals, designers and system developers has invested this project with a focus and synergy it would otherwise have lacked. It should be noted that the designation "art" and "artist" covers all practitioners working in all media.

\section{BACKGROUND}

ArtLog grew out of work done to create an archival strategy for the Centre. Currently there is little or no formal attempt to record information about Irish artists and it was agreed that the Centre would be an appropriate place to start. Originally, the idea was to collect biographical data only but as the idea took hold, horizons expanded and it

$1 \mathrm{http}: / /$ www.tyroneguthrie.ie/

2 http://www.artscouncil.ie 
was decided to go beyond mere information and attempt to capture the creative thought process of artists as they worked. In this context, a log, an art log, was seen as the most appropriate way of doing this.

Furthermore by creating a section of the archive, called Profiles, it would be possible to collect information about the artist and, almost, incidentally, create a database of modern Irish Art. However, there were more questions than answers in the initial stages; the major one being was there any merit in knowing what the artist's thoughts and methods were while they were actually creating the artwork.

\section{AESTHETICS}

There has always been conceptual debate about where meaning lies in Art. Is it in the work, in the audience or in the artist? While this discussion continues, there is general acceptance that a connection exists between the maker and the work [1]. Even Wimsatt and Beardsley in the Intentional Fallacy [2], while decrying inappropriate dependence on biographical interpretation, did not claim that the artist was irrelevant. Indeed it may be that context is one of the most important things to know about a creative work. Some of the more important questions to ask are (1) where and when was the work made? (2) why was it made? (3) who was the artist? (4) what influenced him/her? (5) how did it fit into the ongoing work? [3].

Two studies carried out by Mace [4] and Mace and Ward [5] demonstrated that conceptual development in visual artmaking took place over time. The reflective process was cyclical, with many loops and revisiting of earlier developmental stages. Artists were not working towards solving problems but were expanding and linking concepts to achieve new patterns and connections. Indeed, the only real problem the artist had was in knowing when to stop. The process involved many changes and required the artist to be flexible in his/her approach and follow new directions when they presented themselves. If successful, this is the process that will be documented and preserved in ArtLog.

\section{HERITAGE}

It is not only the artist that is worth recording but documenting the art making process itself is important for the preservation of cultural heritage.

"Inheritance is the essence of heritage but the custodians must concern themselves with what the future will inherit from the present as well as what the present will inherit from the past" Feather [6].

The further away in time we are from an event, the more heavily we rely on documentary evidence to explain it. Manuscripts have always been messages from the dead over time. Previously, these manuscripts have taken the form of letters, diary entries, drafts, typescripts, photographs, financial records and their preservation has more often been accidental than otherwise. This is largely due to the fact that paper is surprisingly robust and will survive benign neglect.

However, increasingly, technology dominates our world. We use mobile phones, send emails, collect our electronic photographs frequently without captions and we create and discard these communications without a thought for what is being lost. Artists keep sketches and notebooks and use graphics packages to play with ideas but do not have a tradition of recording this process as it relates to a work. Writers work on 
personal computers with a word processor and without a conscious effort the result is one final perfect copy without any evidence of process. Poets move words around the screen to find the best pattern: once found this process is lost when the save button is pressed. In short, to replicate the many drafts of a poem by Nobel prizewinners William Butler Yeats or Seamus Heaney, a poet would have to keep multiple files meticulously labelled, date stamped and authenticated and then preserve them by changing the cdrom to a USB key to whatever is next. Realistically this is unlikely to happen. Most people, especially digital natives (as describing those brought up with technology) are careless about technology, only realising how important it is to save after the work is lost. Even if an artist attempts to preserve, digital data by its very essence is fragile. We are in an interim period between paper and pure digital that is dangerous for the preservation of our cultural history.

Since process is in danger of being lost and "manuscripts"are evolving into digital formats that may quickly become unreadable, it is imperative to look to technology for solutions. The very means that destroys evidence of process can become the means of saving it. Only with technology it is possible to find a simple and easy way for artists to document and archive their thoughts and reflections. There is nothing particularly novel is this approach as witnessed by the phenomena of blogging but to do this, organising the content from the beginning with an eye to retrieval and preservation is more challenging. The Tyrone Guthrie Centre where arts practitioners are exclusively engaged in a creative process in an environment dedicated to their creativity provides the ideal testing ground to explore the feasibility of this concept.

\section{FORMULATION OF THE IDEA}

Having established that there is a process to be recorded, there was a lot of discussion about how to proceed. Again, there are more questions than answers. There is a concern that artists are not necessarily self-reflective people. Indeed many artists speak of the feeling that something external to them is assisting the work and are afraid they will lose this if they start being over-analytical. People come to the centre to work: would they be irritated by being asked to spend time inputting into ArtLog? Should individuals be pre-selected and if so what criteria would be used? Should there be parameters around content, a quasi collection policy?

Armed with these questions, a number of informal interactions took place with artists at the Centre. We found some people loved the idea, some hated it, regarding it as a form of control and interference. The vast majority of people were somewhere in between, interested but only just. An interesting initial difficulty was a semantic one. We had been using the term "creative process" in our discussions which we found provoked a negative reaction. We subsequently discovered that artists regarded this as involving the factors outside themselves that they did not wish to explore. We found they were much happier and prepared to embrace the idea when we talked of "artistic process."

Ultimately, it was decided not to exclude people because they were all practioners who had achieved a measure of success in their particular field. Also, given the technology and the low cost of storage, it is cheaper and simpler to collect all data rather than exclude some data. The software would have to be as intuitive as possible and we would need to persuade, encourage and support artists in using the archive. The location of the system would have to be convenient and inviting. We would allow people to input as they liked on the basis that the real value of the archive would be 
apparent in the future and we were not in a position to say what would be important to researchers then. Also, technology makes it possible to identify patterns over large collections of data and we did not wish to pre-empt any possibilities there.

\section{THE ARTLOG COMMUNITY}

Artists are a distinct group of people and when brought together in an environment dedicated to their creativity, informal collaborations can occur in a process that reflects Lave and Wenger's Communities of Practice $(\mathrm{CoP})$ and Legitimate Peripheral Participation (LPP) [7, 8]. In this way the more experienced artists provide guidance and advice to those who are less experienced or still in the early stages of learning their craft. Sometimes small interactions grow into more substantial collaborations. Unless specifically documented, however, these casual and sometimes productive work processes remain unrecorded. It is hoped that ArtLog provides a means to encourage the community to not only record their individual work practice but also to document, in an informal capacity, any collaborations that may emerge during their stay at the centre.

\section{DESIGN OF THE SYSTEM}

Firstly, the project team made a clear distinction between the artist's profile and their practice thus dividing the archive into two sections: the artist's profile and the artist's inputs.

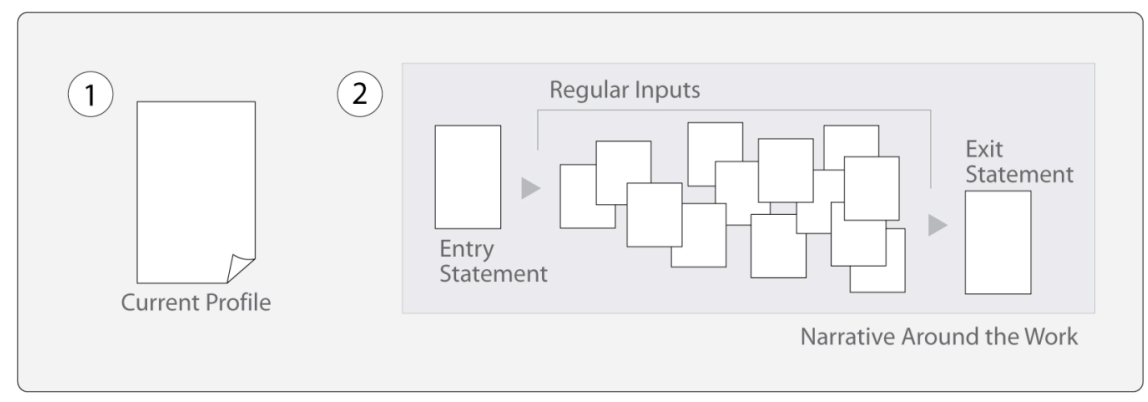

Figure 1: An illustration of how the ArtLog system is organised. The Artist's profile is thought of as separate from their inputs. While the profile attempts to document their work to date, the inputs, when collated, seeks to emphasise the narrative surrounding the artist's work practice.

\section{Profiles}

On visiting the centre it is mandatory for an artist to complete a 'profile'. At a very minimum this will include their biographical details but they will be encouraged to outline their artistic history to date. However, this is entirely a matter of personal choice. With each additional visit the artist is invited to augment their profile with details of the work they have carried out during the intervening period. In this way an artist's profile is viewed as a dynamic record that has the potential to document their artistic development over time.

Secondly, all residents at the Centre are engaged in active creation albeit at different stages in the process. They are there primarily to work on a specific project. With this in mind the artist is invited to complete an opening or entry statement, outlining any ambitions or plans they have for their work. Similarly, before leaving, the artist is invited to complete a closing or exit statement summing up their experiences both with 
regard to the work and their stay at the Centre. Both statements are used to bookend the artist's visit.

\section{Inputs}

A different method was devised for artists to record their reflections on their practise. Here the artist is invited to leave a series of diary-like 'inputs' on a voluntary basis, each describing aspects of their working day, or indeed thoughts or expressions they may feel as relevant to their work. Originally an input was viewed as text-based. However, further discussions, amongst domain experts and the project team, highlighted the possibility of an artist submitting a piece of video as an input ${ }^{3}$. This was proposed to include artists who may feel that written inputs are insufficient in describing their work practices. Similarly, some artists may feel more comfortable with video inputs or, indeed, a variety of media types combined into a single ArtLog input. For example, an artist may choose to create an input combining video with text and photos. The overall approach provides an intuitive and expressive way for the artist to document the ways in which they go about their art. The entrance and exit statements coupled with the inputs help to create a symbiotic narrative around the work. It is this narrative that the ArtLog system seeks to capture and make available to scholars.

Finally, the system provides a mechanism for artists to add comments about their own inputs or those belonging to other artists. It is anticipated that artists' comments may reflect the social dynamics of the centre. Moreover it provides artists with a forum to informally discuss the artistic process. It is also worth noting that every input to the system is treated as a valuable asset. Each is archived according to a comprehensive archival policy that preserves the input's integrity and the artist's copyright. In fact there has been much recent debate regarding the authenticity of artworks. Within this context, ArtLog not only seeks to document the artistic process but also provides context, authenticity and provenance to a work of art.

\section{SEARCH AND RETRIEVAL}

From the outset the project team identified a comprehensive archival strategy. This involved organising ArtLog content according to agreed upon set of standards in terms of cataloguing rules (drawn up by professional cataloguer), the metadata schema for inputs (METS), and a consistent vocabulary for indexing (the Library of Congress Subject Headings (LCSH)) (Figure 2). METS was chosen for its ability to deal with complex objects and its technical and preservation metadata. The LCSH is a comprehensive subject-based thesaurus used in libraries for the purpose of cataloguing. Here it has been subdivided into a set of twelve hundred terms and organised into a hierarchy by a professional librarian. This hierarchy will be used to support query expansion for the retrieval of ArtLog inputs. If, for instance, a user searches for portrait painting, the broader category of art will receive a weighting corresponding to its place in the hierarchy. The approach is reliant on a professional cataloguer who intermittently indexes new ArtLog inputs according to the LCSH.

\footnotetext{
3 Although it is anticipated that the majority of inputs will be text-based, different types of media raise the broader question of interpretation and preservation. Different media formats may, for instance, place a large burden on the cataloguer. This is an open question that will have to be re-addressed at a later date.
} 


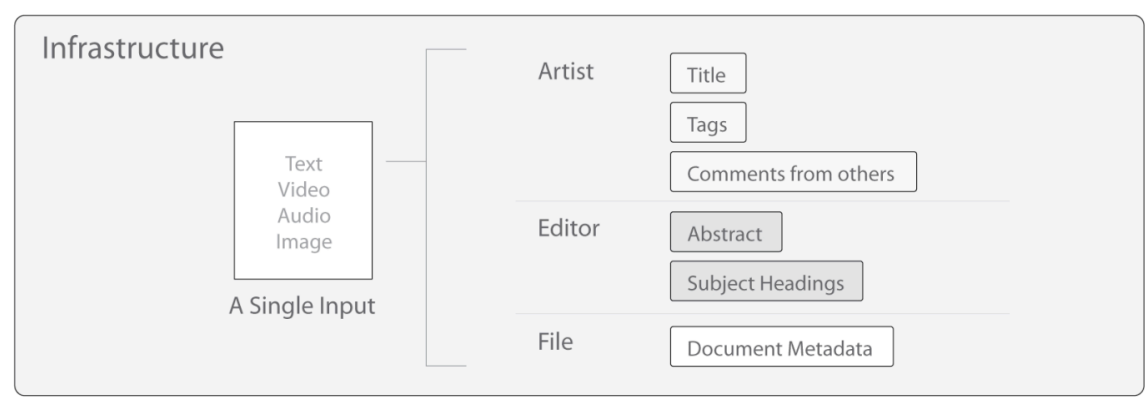

Figure 2: The infrastructure and organisation of metadata in the ArtLog system.

However, the intention is not to take the content out of the hands of the community. To this end social tagging - a popular means to encourage user-generated taxonomies has been included in the system as a method for artists to organise and connect with their content. The artistic community at the Centre is a very distinct one with, it has been suggested, a very specific vocabulary. In this context tagging not only provides a means for the community to identify with their content but also presents a platform to promote the emergence of a Folksonomy [9]. Further to this, it is suggested that tags can be used to improve search and retrieval. Research has been conducted into using tags in this way. Both [10] and [11], for example, have examined how indexing social tags can impact search results. Similarly, [12] and [13] have investigated approaches to organising tags according to inherent tag cloud semantics. However, these approaches have concentrated on large-scale unstructured web content as created by users of the social book-marking site Delicious ${ }^{4}$. ArtLog is organised differently. The content is created within a closed domain - documenting the artistic process, developed by a closed community - the artists, and professionally catalogued according to a subset of the LCSH. Contemporary approaches to information retrieval are often conducted upon a ranking basis. Each item in the result set receives a ranking in relation to the user's keywords. The ways in which this ranking is created, however, differ greatly. In ArtLog, the ranking of each input will be generated from the relationship between the LCSH, the community's tags and, possibly, the inclusion of a free search algorithm. The approach is not yet finalised, as it will require some further experimentation when the system is live. Nevertheless, it does present an opportunity to use the immediate feedback mechanism of tags to improve the precision of information retrieval.

\section{COLLABORATION ON THE PROJECT}

The ArtLog project is being undertaken as a close collaboration between researchers from the Humanities and the Sciences. User-centred design is seen as having a pivotal role in how the system is conceived, developed and finally presented to the broader community at the Tyrone Guthrie Centre. The approach of the project team was to place the user, or in this case the artist, firmly in the centre of the design process. Initially this involved concentrating on developing a working prototype that went through an iterative design process culminating with the live production version (as illustrated in Figure 3). Although the graphical design of the system had been discussed, and preliminary sketches undertaken, it was not until development was complete that the project team conceived and later applied a new concept and design. 

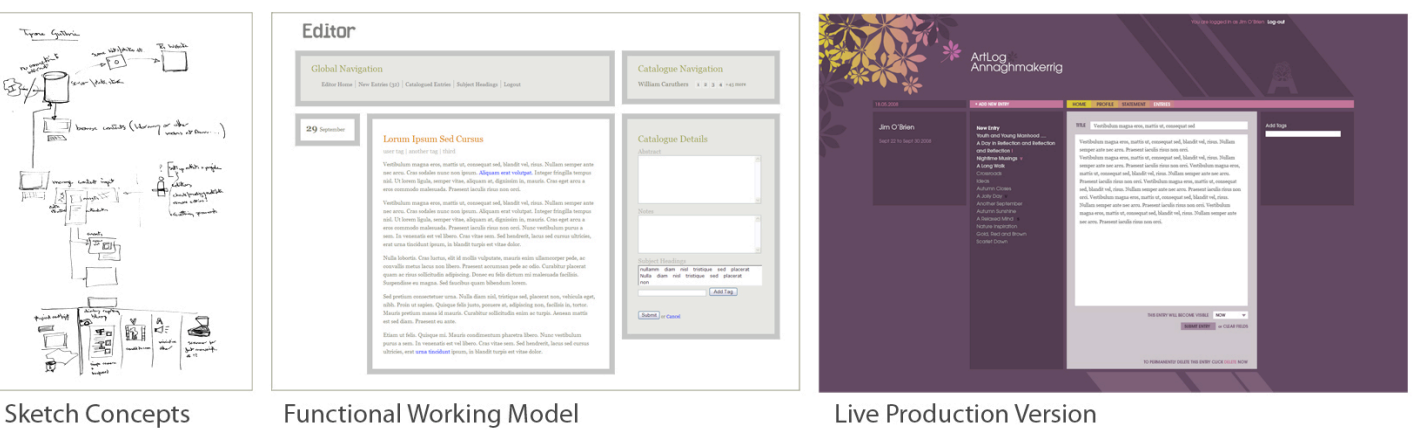

Figure 3: The development of ArtLog, from conception to production.

However, there were further user considerations. The ArtLog Editor, or the user whose duties include archiving the artist's entries, has also very important role to play. ArtLog is, after all, a professionally maintained scholarly archive, and it was therefore important to develop a suitable archival policy. The implementation of a considered preservation policy helps to emphasise the process of collaboration on the project. A professional DIT librarian helped to identify a suitable metadata schema, in the form of METS, and a consistent vocabulary, in the form of LCSH. However, the project team also collaborated closely on developing the role of the Editor, who will also have considerable experience in the library sciences. Apart from user-centred design and the complement of library science, the project is also supported by a strong connection with the discipline of computer science. This is illustrated by the innovative approach to information retrieval, incorporating the relationship between the community's tags and the LCSH hierarchy, and the schematic design and implementation of the ArtLog system. Indeed, it is in this way that the ArtLog project serves to illustrate more contemporary approaches to information management whereby several practitioners from a range of interrelated disciplines collaborate on a central activity.

\section{SUMMARY}

This paper has outlined the ArtLog project as a novel approach to documenting the artistic process. The project grew out of initial discussions to create a comprehensive archival strategy for the artist's retreat at the Tyrone Guthrie Centre, Annaghmakerring, Co. Monaghan. Drawing from related work in aesthetics and heritage, the design of the ArtLog system intends to facilitate the artist to reflect upon and document their work practice. The project is in the early days of implementation and it will be interesting to see how it progresses. The expectation is, as with any archive, it will be slow to grow and a programme of education, information and persuasion will be required to encourage participation. As with any creative project it will be interesting to see do we, like the artists, end up making connections and seeing patterns that were not anticipated at the outset. Nevertheless, the goal of empowering the artistic community through the use of technology will continue to focus the work carried out on this project.

\section{REFERENCES}

[1] TOWNSEND, D., Introduction to Aesthetics. 1997: Wiley-Blackwell.

[2] WIMSATT Jr W K and Beardsley M C: The Intentional Fallacy, in The Verbal Icon: Studies in the Meaning of Poetry. 1954, University of Kentucky Press.

[3] BLOOMER, C M: The Principles of Visual Perception 1990: TAB Books Inc. 
[4] MACE M.-A: Towards an Understanding of Creative Thought through a Qualitative Approach. Creative Research Journal, 1997. 10(2 \& 3): p. 265-78.

[5] MACE, M-A and Ward, T: Modelling the Creative Process: A Grounded Theory Analysis of Creativity in the Domain of Art Making. Creativity Research Journal, 2002. 14(2): p. 265-78.

[6] FEATHER, J: Managing Preservation for Libraries and Archives: Current Practice and Future Developments. 2004: Ashgate Publishing.

[7] LAVE J. and Wenger E: Situated Learning : Legitimate Peripheral Participation (Learning in Doing: Social, Cognitive \& Computational Perspectives), in Situated Learning : Legitimate Peripheral Participation (Learning in Doing: Social, Cognitive \& Computational Perspectives), R. Pea, J.S. Brown, and C. Heath, Editors. 1991, Cambridge University Press. p. 29.

[8] WENGER, E, McDermott, R, and Snyder, W M: Communities of Practice and Their Value to Organization, in Cultivating Communities of Practice. 2002, Harvard Business School Press: 4.

[9] VOSS, J: Tagging, Folksonomy \& Co - Renaissance of Manual Indexing? In $10^{\text {th }}$ International Symposium for Information Science. 2007: Cologne.

[10] HEYMANN, P, Koutrika, G, and Garcia-Molina, H: Can social bookmarking improve web search? In Proceedings of the international conference on Web search and web data mining. 2008, ACM: Palo Alto, California, USA.

[11] SHENGHUA, B, et al: Optimizing web search using social annotations, in Proceedings of the 16th international conference on World Wide Web. 2007, ACM: Banff, Alberta, Canada.

[12] SCHWARZKOPF, E, et al: Learning the Structure of Tag Spaces for User Modeling, in Proceedings of the 11th international conference on user modelling. 2007: Corfu, Greece.

[13] BEGELMAN, G, Keller, P and Smadja F: Automated Tag Clustering: Improving search and exploration in the tag space, in The 15th International World Wide Web conference (WWW2006). 2006: Edinburgh, Scotland. 